\title{
An initial assessment of community representation and diversity within UK geophysics
}

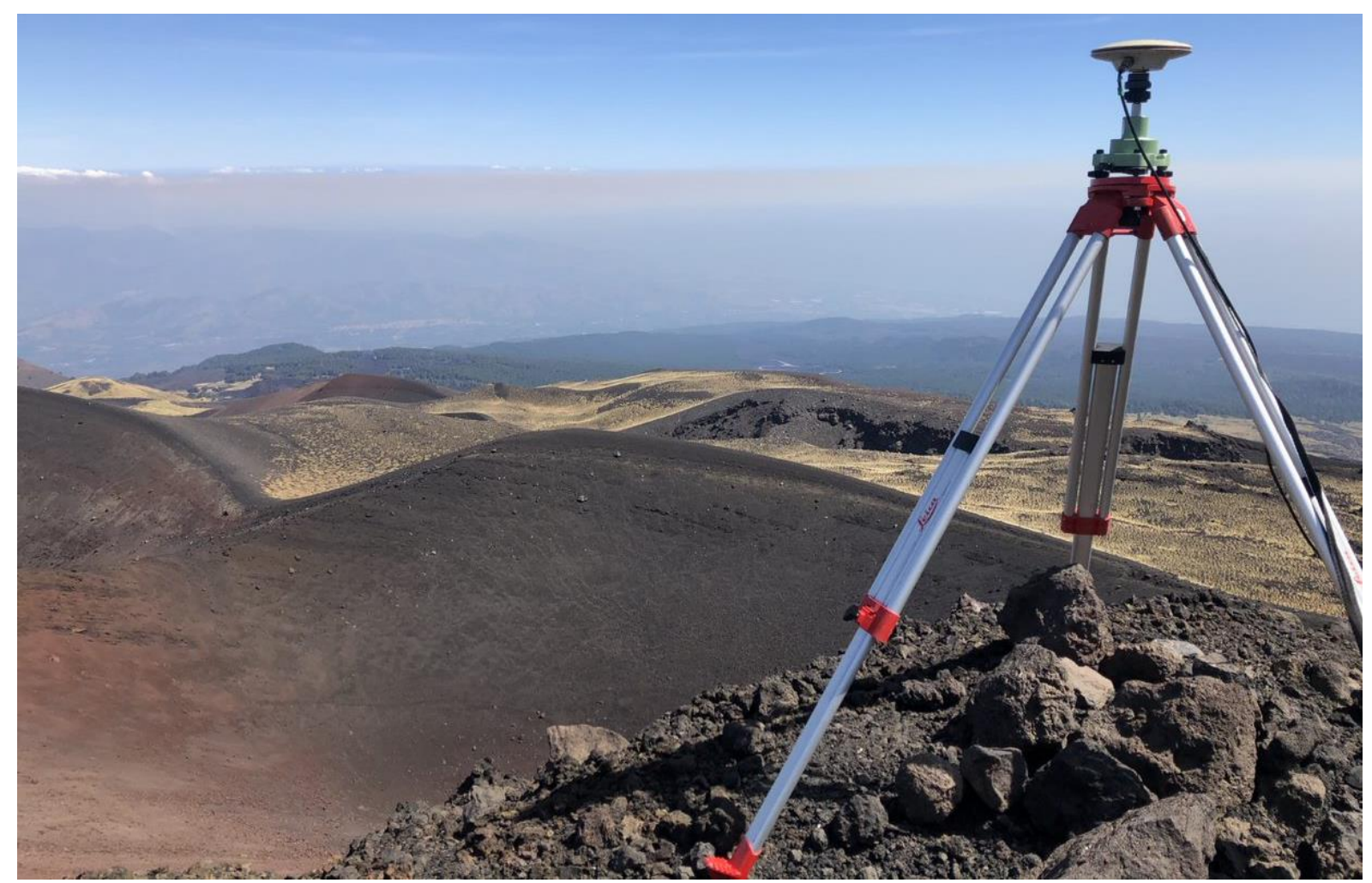

Christopher J. Davies ${ }^{1}$, c.davies@leeds.ac.uk Stephen P. Hicks², s.hicks@imperial.ac.uk Lauren Cox ${ }^{3}$, lauren.cox.15@ucl.ac.uk Sheila Peacock ${ }^{4}$,geophyspeacock@myphone.coop

1. University of Leeds; 2. Imperial College London; 3. Birkbeck, University of London; 4. AWE Blacknest

This paper is a non-peer reviewed preprint submitted to EarthArXiv

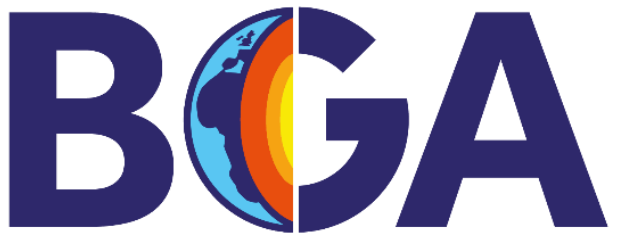

BRITISH GEOPHYSICAL ASSOCIATION 


\section{Executive summary}

The British Geophysical Association (BGA) is a Joint Association of the Geological Society of London (GSL) and the Royal Astronomical Society (RAS) that aims to promote the subject of geophysics, and to strengthen the relationship between geology and geophysics in the UK. As such, engagement with all members of the geophysics community is integral to our purpose, and we recognise that the Earth Sciences in general are one of the least diverse STEM subjects. This report is our preliminary assessment of current community engagement with the academic research activities of the BGA, but also with geophysics as an academic subject. The data within this report comes from incomplete sources and so there are gaps in our knowledge that should be addressed in the future. Nevertheless, it provides an initial, albeit crude, perspective of the past and current level of community representation, diversity and inclusion within UK geophysics. We also provide some information on the range of research fields falling within BGA-endorsed activities.

HESA data for 2013-2019 show a declining intake of undergraduates and postgraduates on Geophysics courses from 2015. Detailed information on ethnicity and gender is not known; however, the data show a low representation of Black and Minority Ethnic groups, which we expect to feed into a low representation in the UK Geophysics research community. Going forward, the BGA aims to gather more detailed ethnicity, diversity and inclusion (EDI) information from our community to better target engagement efforts.

The Bullerwell Lecture is the BGA's most prestigious annual award and has been presented since 1981. Gender data for the award indicate that, while historically recipients have been predominantly male, more recently progress towards a more equitable gender balance has been made over the last decade. There does however remain a large imbalance between white and non-white recipients. The Postgraduate Research in Progress (PGRiP) Conference is an annual, postgraduate-run event held at a different host institution each year. Conference records from 2008-2019 indicate that female attendee numbers have never exceeded male attendees. This disparity is reflected in the presenter numbers, with only the 2012 conference having a greater proportion of female-led talks and posters. The prizes awarded for best poster and talk during the conference have historically been dominated by males and white ethnicities. Similarly, available data about the composition of the BGA committee shows a traditional dominance of males, which has not significantly improved over time.

This report has been produced with the aim of informing both the BGA and the wider Geophysics community and is concluded with a set of recommendations for both parties. The BGA Committee pledges to improve the inclusivity of the BGA by:

- Appointing an EDI Officer

- Improving accessibility to the annual PGRiP conference

- Implementing unconscious bias training for judging panels and applying EDI best practices to the assessment of any prizes and awards

- Actively promoting the work of under-represented members of our community and of minorityfocussed peer support groups within Geophysics

- A more inclusive approach to advertising BGA committee roles and their election.

As a community, we must work to improve the uptake and retention of Geophysics courses at university level, through greater investment in school-level outreach programmes to attract students from all educational backgrounds, and targeted support for undergraduate students. The BGA will look to work with the GSL, RAS, and other groups to consider how to improve the accessibility of geophysics. This might be facilitated by BGA reps joining relevant committees and working groups. 


\section{1) Introduction}

The British Geophysical Association (hereafter, BGA) is a scientific society that aims to promote the subject of geophysics, and particularly to strengthen the relationship between geology and geophysics in the UK, by holding meetings and courses, conferring awards, distributing funds for fieldwork and other research support, and by encouraging the publication of the results of research. The BGA is jointly affiliated with its parent organisations, the Royal Astronomical Society (RAS) and the Geological Society of London (GSL). The Earth Sciences in general suffer from a lack of diversity and are likely to be one of the least diverse STEM fields [Bernard \& Cooperdock, 2018]. This overall conclusion is also supported by data from the UK [Dowey et al., 2021]. Thus, geophysics is likely to suffer from similar issues. However, no attempts have been previously made to document or report on the level of diversity at or in BGA activities, vital for tracking potential changes in Equality, Diversity and Inclusion (EDI) levels over time.

Here we provide the first dataset and analysis of EDI and community engagement within BGAassociated activities and membership, following similar efforts made by the Volcanic and Magmatic Studies Group (VMSG) [Gibson et al., 2020] and the Tectonic Studies Group [Bubeck \& Farrell, 2019], both affiliated with the GSL. The report focuses on the BGA's two primary activities-the Bullerwell Lecture, which is awarded to a UK geophysicist who is within 10 years of obtaining their $\mathrm{PhD}$, and the Postgraduate Research in Progress (PGRiP) Conference-and so most directly pertains to early career researchers in academic institutions. Nevertheless, it is hoped that this work can form a useful reference point for future studies.

The information presented in this report has been collated from historical records held by the BGA, alongside publicly accessible sources such as personal websites. From Section 3 onwards, personal data such as gender and ethnicity were not collected at the time and so inferences have been made based on the information available and gender assignment is binary. We acknowledge that this is an imperfect approach which must be improved in the future, but nevertheless feel that, in the absence of more precise data, this information can still offer important insights into the current status of EDI and community engagement with BGA activities, providing a baseline for future comparisons. It will also help to guide the pathway forward.

\section{2) Student representation}

In this section we examine the representation within UK Geophysics at undergraduate (UG) and postgraduate (PG) level. This provides crucial context for interpreting EDI data in Geophysics at PG levels and beyond. Figure 1-Figure 4 below show data acquired from the Higher Education Statistics Agency (HESA) in December 2020. The data covers taught BSc and MSc programs and PhD programs. Numbers are reported as Full-Person Equivalent (FPE), which is not quite the number of students: it accounts for the fact that students can study joint courses (e.g. for a course comprising $50 \%$ geology and $50 \%$ geophysics, the FPE in 0.5 ). Data show first year entry only, which for UG courses includes students that have entered directly into years two or three. Note that the HESA data is rounded to the nearest 5 and any number lower than 2.5 is rounded to 0 . UG data does not include the following courses:

- Oxford (Earth Science).

- Bristol (Geophysics).

- Cambridge (Earth / Natural Science).

- Royal Holloway (Geoscience).

- Newcastle (Earth and Environmental Science).

- Swansea (Environmental Geoscience).

Page | 3 


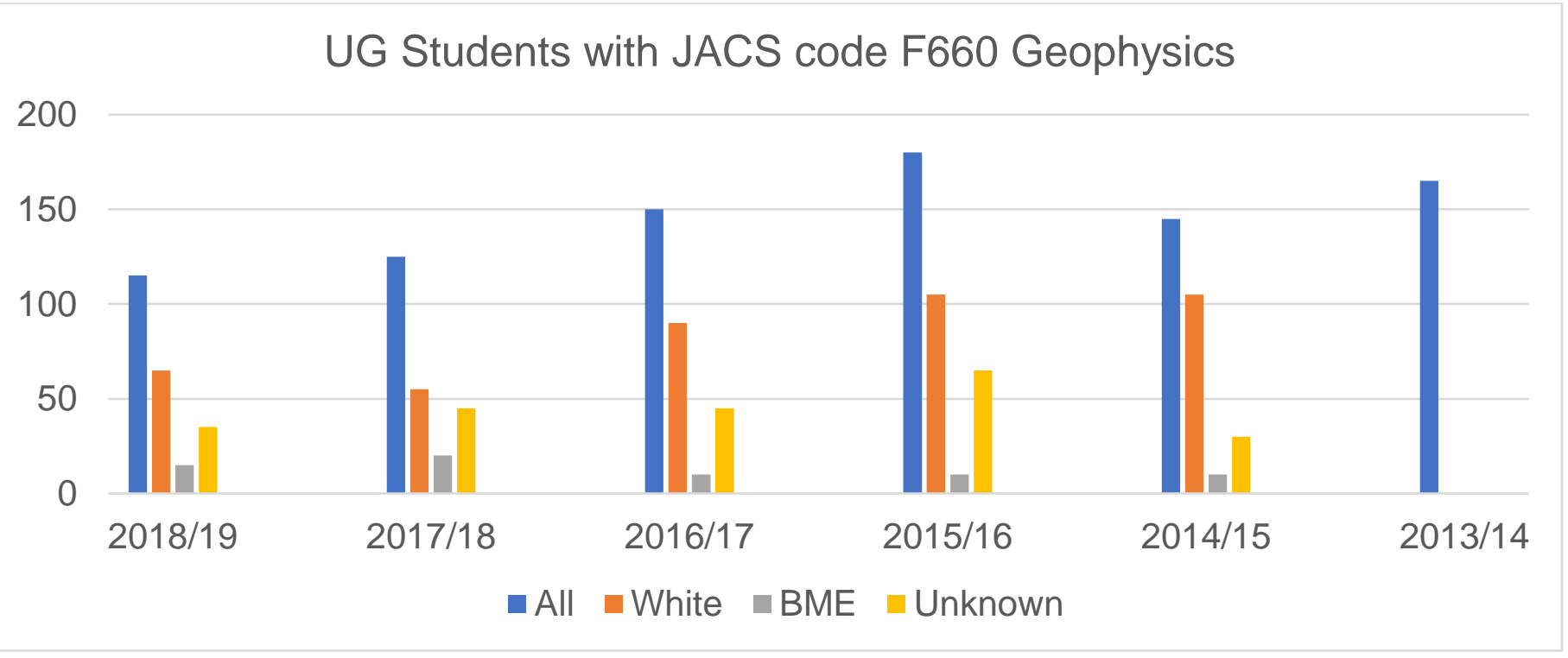

Figure 1. UG students enrolled on programmes that use the Higher Education Statistics Agency (HESA) Joint Academic Coding System (JACS) code F660 for different years. The JACS system is used by HESA to classify academic subjects and modules.

\subsection{Undergraduate and taught postgraduate courses}

Figure 1 shows numbers for all UG students registered on programs that use the HESA Joint Academic Coding System (JACS) code F660 Geophysics, which includes BSc and integrated MSc courses. For this program the HESA data supplied for this report contained ethnicity data split into categories of "White", "BME" and "Unknown". In the following we use the term "BME" to refer to the categorisation used in the HESA data, acknowledging that some may find this very coarse ethnicity classification problematic because it combines different identities and conceals lived experiences felt by a single race or ethnicity. The proportion of students sampled by the HESA data that responded as $\mathrm{BME}$ is $13 \%, 16 \%, 7 \%, 6 \%$ and $7 \%$ going back from $2018 / 19$. For context, the Office for National Statistics (ONS) data on Ethnicity and National Identity in England and Wales ${ }^{1}$ revealed that $86 \%$ of the population in 2011 gave their ethnic group as "White", while $18.5 \%$ of $18-24$ yearolds came from Black, Asian, 'mixed' and 'other' backgrounds [Dowey et al., 2021]. The comparison between ONS and HESA data is not trivial because the two datasets sample different populations in different ways. Moreover, the ethnic group is unknown for a high proportion of the HESA dataset. Taken at face value the data suggests that BME students are under-represented in Geophysics compared to the UK population, which is consistent with the conclusions of Dowey et al. [2021], who conducted a more detailed analysis of representation within the Geosciences in general.

Figure 2 shows the number of UG students registered on programmes with 'Geophysi' in the course title. This search returns courses that are assigned the following JACS codes: F170 Physical Chemistry, F510 Astrophysics, F600 Geology, F640 Earth Science, F660 Geophysics, F661 Exploration Geophysics, F700 Science of Aquatic and Terrestrial Environments and F761 Meteorology. 


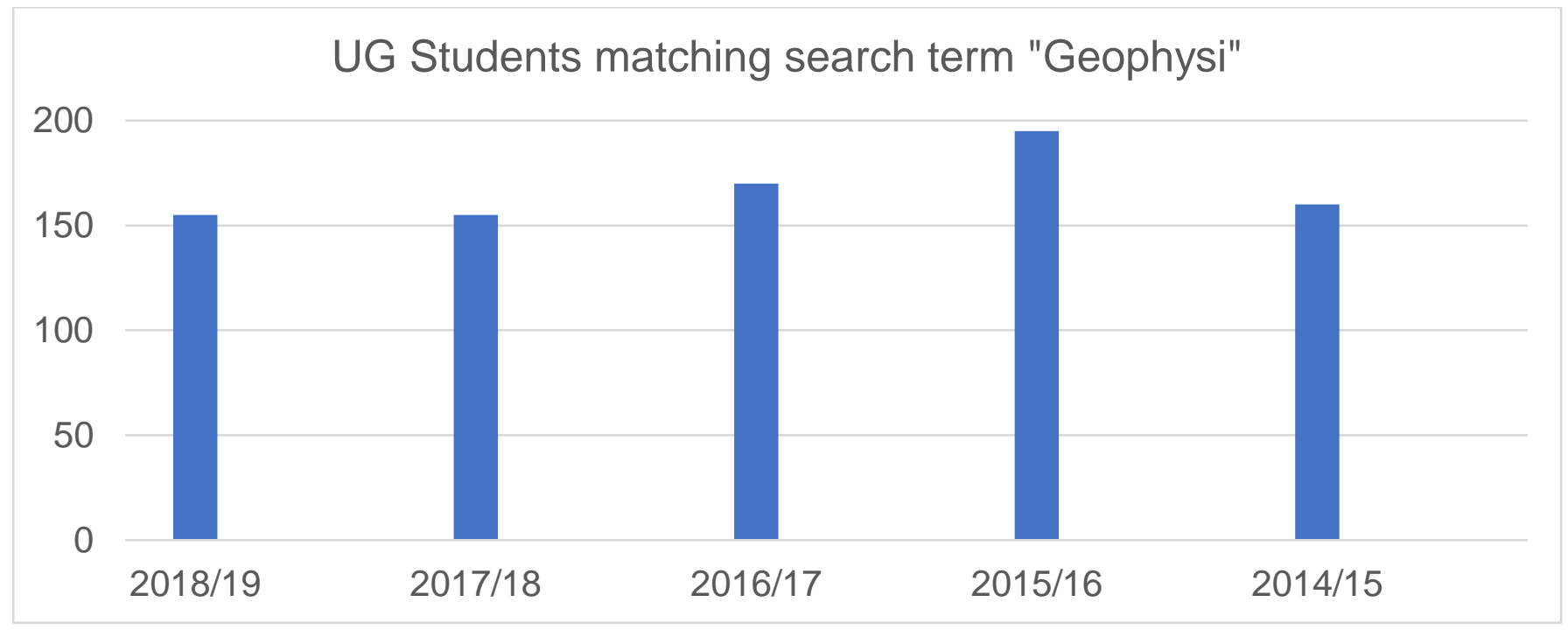

Figure 2. UG students registered on programmes matching the search term "Geophysi" for different years

Figure 3 shows the number of taught postgraduate (PGT) students registered on programmes with 'Geophysi' in the course title. These are: "Exploration Geophysics", University of Leeds; "Struct Geology With Geophysics", University of Leeds; "MSc Geophysical Hazards", University College London; "Degree Of Master Of Science In Geophysics", University of Aberdeen.

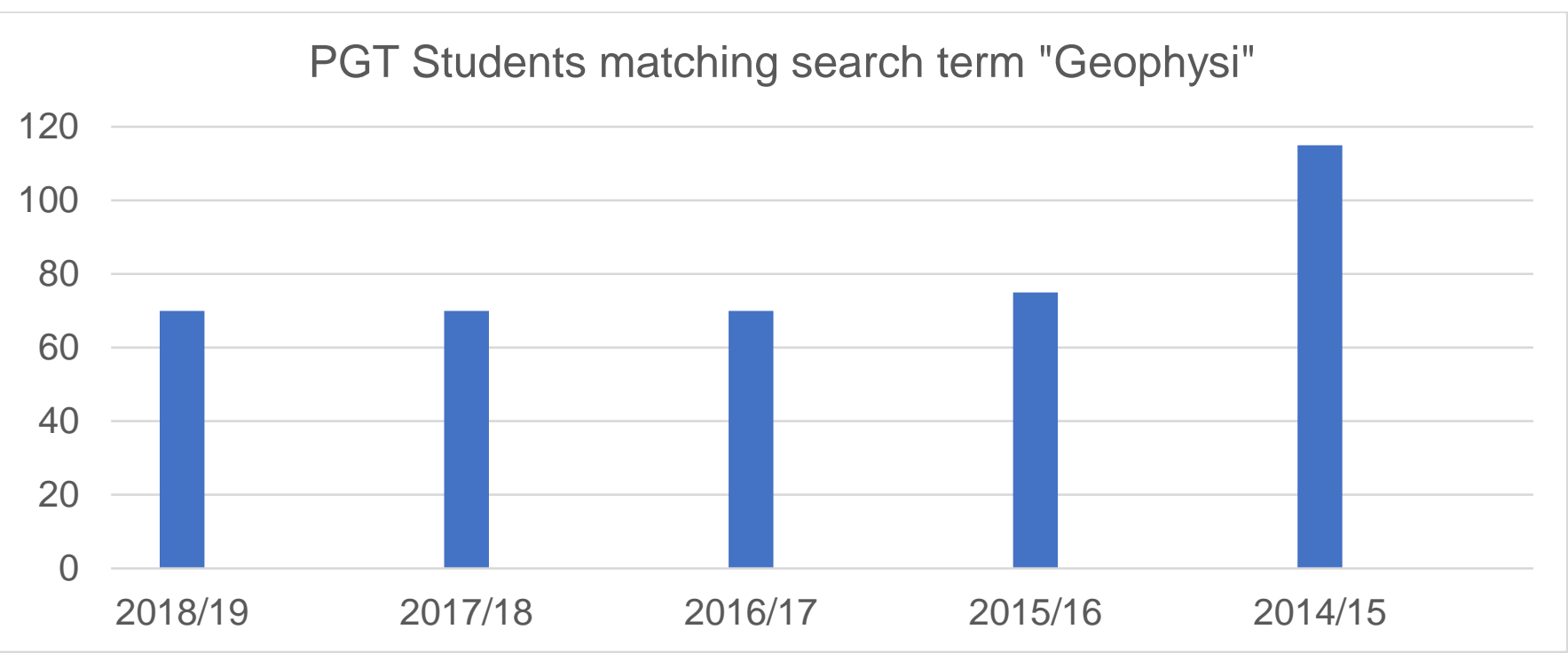

Figure 3. PGT students registered on courses matching the search term "Geophysi".

Figure 1 shows that there have been between 115 and 180 UG students per year over the 6-yr period considered, while the broader "Geophysi" search shown in Figure 2 gives a more stable trend with 155-195 UG students per year. PGT data is only available for the "Geophysi" search, which shows a range of 70-115 students over the same period. Since the PGT courses in this search all focus on Geophysics, we use the numbers in Figure 3 as a proxy for the number of Geophysics PGT students.

According to Figure 1 at any one time there were at least 345 geophysics UG students (115 for 3 years), while the most recent 3 years covered by this data gives 390. Figure 2 suggests an upper bound on UG student numbers between 465 (3 times the 155 students in 2018/19) and 480 (the last 3 years). Adding on the PGT data and UG students from omitted institutions suggests a range of 450-550 Geophysics UG students at any one time.

Page | 5 
The EDI data in Figure 1 convey two main points. First, there is significant under-representation in Geophysics of individuals that have identified as "BME" in HESA data with no compelling evidence of a more recent upturn in numbers. We must therefore expect significant underrepresentation of this group at PG level and within Geophysics faculty and this is indeed what we find below. Second, there is a large proportion of students for which EDI information is unknown. There is urgent need for improvement here, both to assess current EDI levels and measure the effect of remediation steps in the future.

\subsection{PhD studies}

HESA data for PhD students is shown in Figure 4. This data was obtained using the JACS code F6 Geology, which includes the following subjects: Geology; Applied Geology; Industrial Geology; Engineering Geology; Mining Geology; Exploration Geology; Geotechnology; Marine Geotechnology; Earth Science; Palaeontology; Geoscience; Quaternary Studies; Hydrogeology; Mantle \& core processes; Land-atmosphere interactions; Geological oceanography; Geophysics; Exploration Geophysics; Geochemistry; Geohazards; Seismology and Tectonics; Volcanology; Geology not elsewhere classified. Evidently the F6 data over-estimates the number of Geophysics; if we crudely estimate that $50-75 \%$ of the students returned by the F6 search are studying Geophysics-related PhDs this suggests a range of approximately 200-300 Geophysics PhD students at any one time.

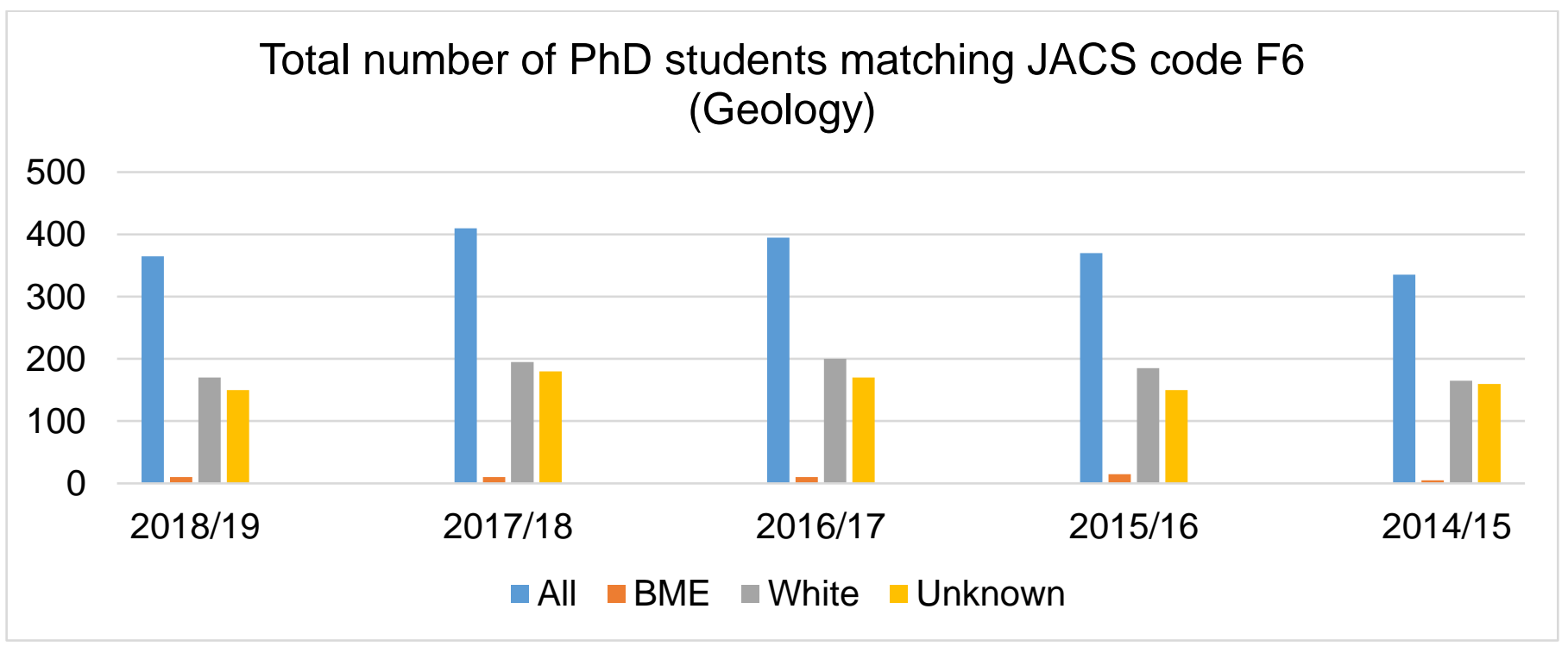

Figure 4. PhD students per year registered on courses matching JACS code F6 (Geology).

As with the UG data above, Figure 4 shows a significant and persistent under-representation in Geology (and by extension Geophysics) of individuals identifying as BME in HESA data PhDs and a high proportion of students for which EDI information is not known. We must therefore expect significant under-representation of these groups in PG level and within Geophysics faculty and this is what we find below.

\section{3) Bullerwell Lecture}

The Bullerwell Lecture is awarded annually and is given to "an outstanding early career scientist" in geophysics. There has been a total of 40 Bullerwell lecturers; the first was in 1981. For each lecturer we have obtained data on gender, ethnicity, presentation topic and institution. Gender data were obtained from personal websites using names and visual inspection of profile pictures where available. We acknowledge that this data collection method is inadequate; however, it was also the 
best method available given the limited information in past records. It is also a starting point upon which we can improve using proper data gathering methods as described in the Section 6 below. The data (Figure 5) show that overall, there are substantially more male winners that female winners. However, the division from $2010-2020$ has been equal.

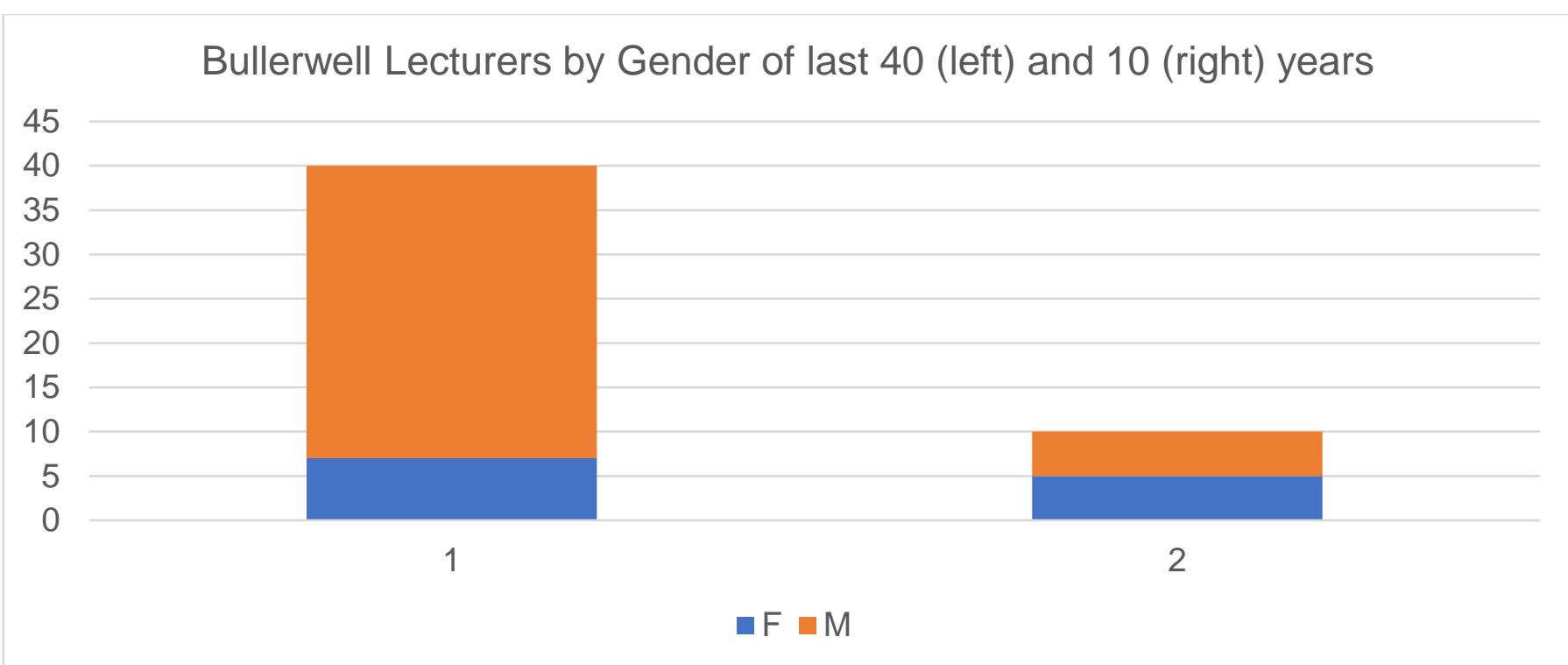

Figure 5. Gender balance across the 40 Bullerwell Lecturers. F refers to Female, $M$ to Male.

Ethnicity is very hard to gauge without dedicated EDI survey data. The crude approach taken here was to assign each winner as either White (W) or Non-White (NW) using available information on the internet. Clearly, this is very imprecise, but may be somewhat useful in the case where there is a large disparity between the values of $\mathrm{W}$ and NW. Figure 6 shows that this is indeed the case.

\section{All Bullerwell Lecturers by Ethnicity}

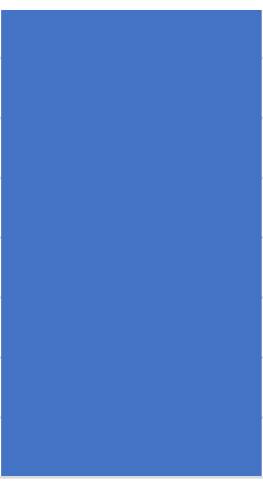

W

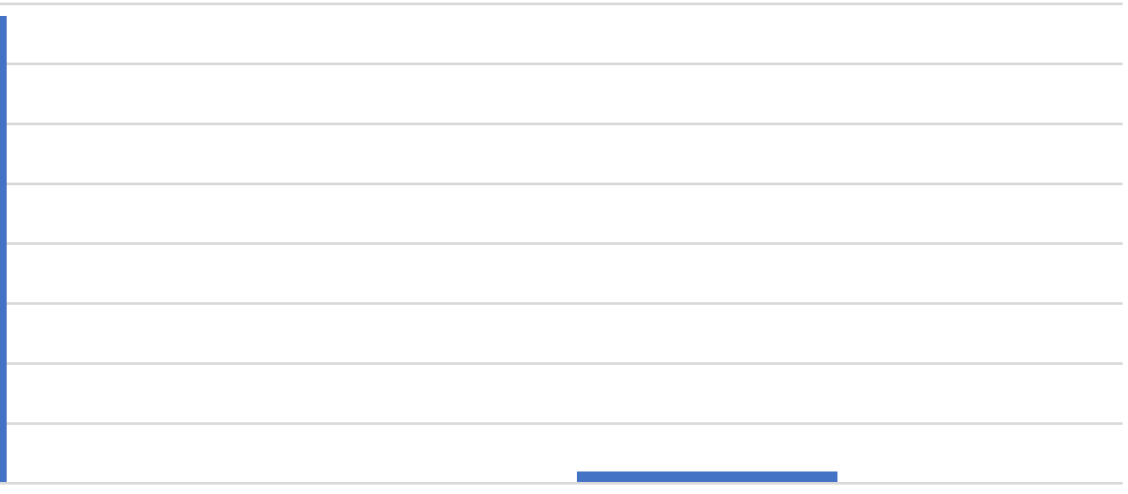

NW

Figure 6. Ethnicity, defined as "White" (W) and "Non-White" (NW), for the 40 Bullerwell Lecturers.

Next, we investigated the subject areas represented by Bullerwell Lecturers to assess whether they cover the breadth of topics that might be expected to be relevant to UK Geophysics. We assigned each speaker a primary research topic from the following list: Seismology (lithosphere), seismology (deep Earth), tectonics, rock physics, geodesy, glaciology, geomagnetism, paleomagnetism, volcanology, mantle dynamics, and exploration. This division is obviously non-unique, and the results would probably change if other divisions were used though this has not been tested. The topics are also not mutually exclusive, e.g. a study may combine seismic observations of the mantle 
with a dynamical model, and so the categorisation should be taken as the primary focus of a lecture. We also attempted to categorise lectures by the region of the Earth that was the primary focus of the talks but found this to be rather uninformative.

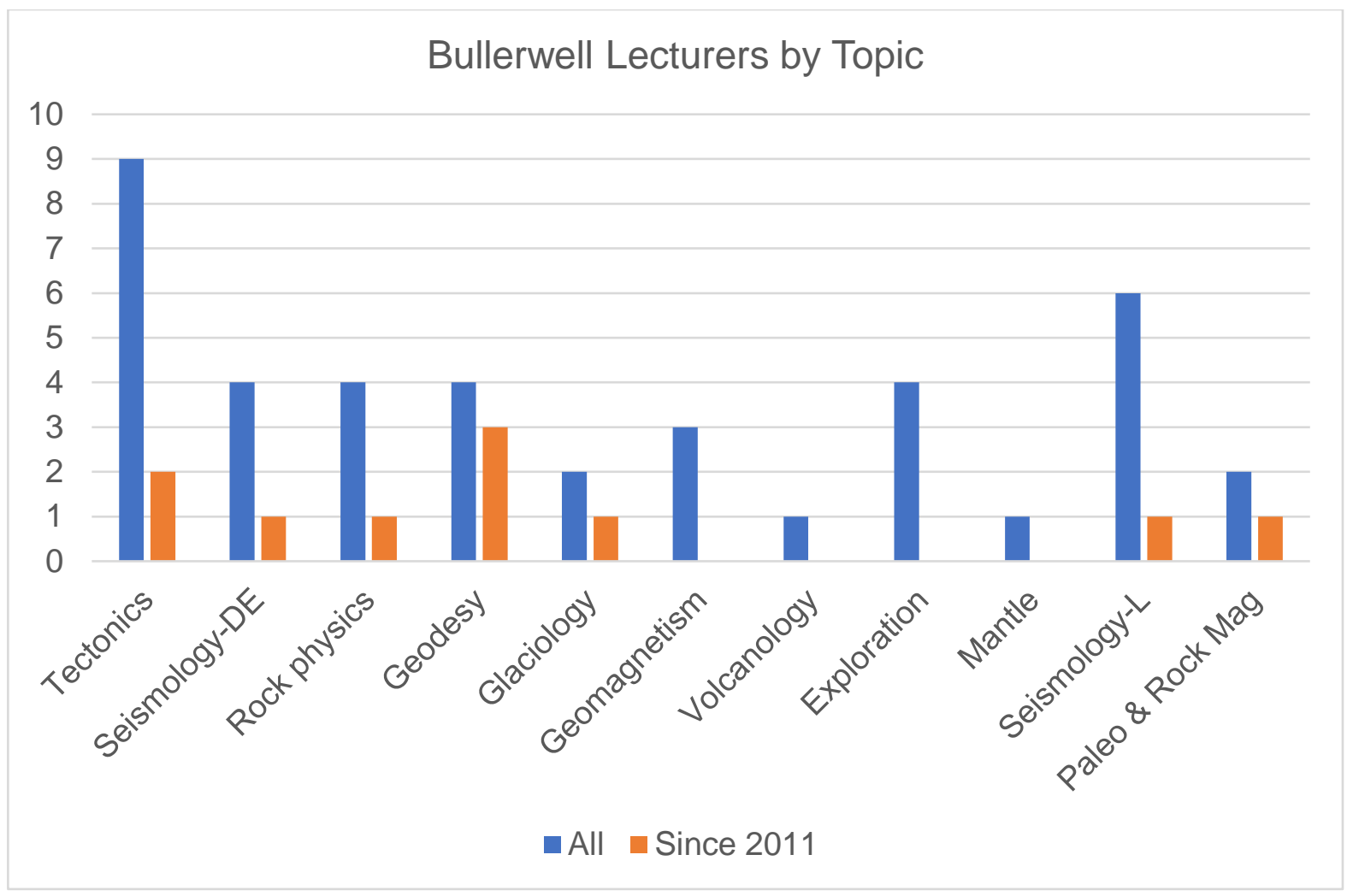

Figure 7. Primary topic covered by the 40 Bullerwell Lecturers.

Figure 7 shows that there seems to be a good spread of Bullerwell lecture topics from deep Earth to near surface processes, which perhaps reflects the depth of research in the UK. Recently there has been less focus on exploration geophysics, perhaps because these researchers are affiliated with other associations, while mantle dynamics and volcanology have only received 1 award each over the last 40 years. The BGA could consider strengthening links with related groups such as the Near Surface Geophysics Group, and the Volcanology and Magmatic Studies Group.

Finally, we looked at the institutions represented by the Bullerwell Lecturers (Figure 8) to assess whether the BGA is selecting across the breadth of UK institutions. There is again a reasonable spread, both recently and overall, with only Leeds and Cambridge having notably more Lecturers than other institutions. Some institutions with strong traditions in Geophysics - for example, Cardiff, Aberdeen and UEA - have never had a Bullerwell Lecturer. The BGA could consider how it advertises the Bullerwell Lecture selection process in order to reach and engage as wide a range of nominees as possible. 


\section{Bullerwell Lecturers by Institution}

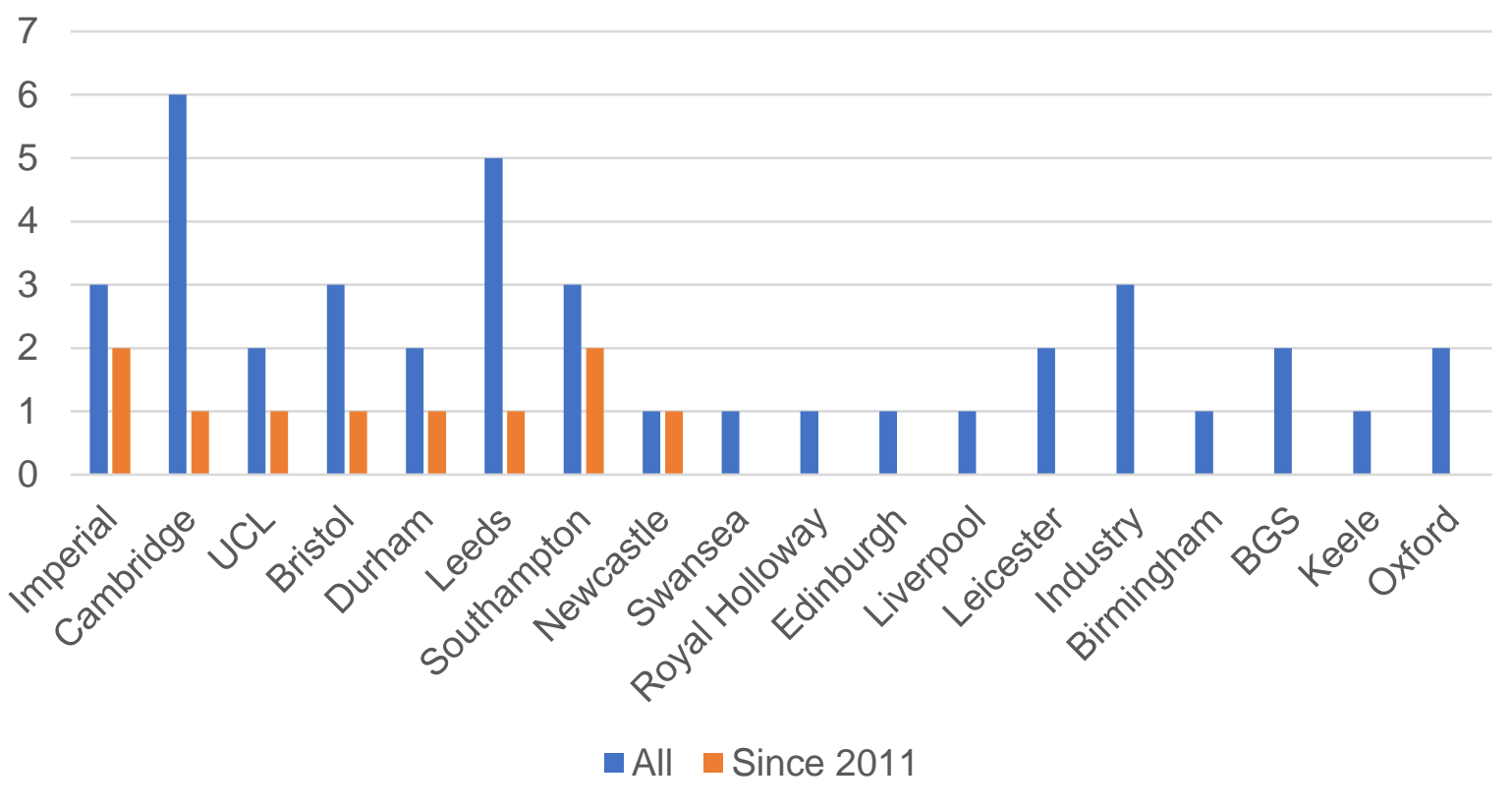

Figure 8. Bullerwell Lecturers by institution.

\section{Postgraduate Research in Progress conference (PGRiP)}

PGRiP data have been retrieved from the BGA archives. Where possible we have obtained information from lists of delegates. Group photos have also been used to obtain the number of total participants and total female participants in instances where delegate lists contained only the list of presenters (Table 1). In a given year there are generally $\leq 50$ participants, which should be taken within the context of the expected 200-300 Geophysics PhD students estimated above. There is quite a large variability in attendance from 2008 - 2019. There are also always fewer female attendees than male (though we re-state that this classification scheme and data collection has been overly simplified). The BGA committee should therefore consider whether there is scope for broadening the participation at PGRiP.

Table 1. Participant data for each PGRiP conference since 2008. "Total" indicates the total number of participants, of which the female proportion is stated. The asterisk indicates 10 submissions from overseas.

\begin{tabular}{|r|l|r|r|r|c|}
\hline & & \multicolumn{1}{l|}{ Total } & Female & Presenters & Source for total \\
\hline 2019 & Bristol & 52 & 21 & 42 & Group Photo \\
\hline 2018 & Cardiff & 39 & 10 & 26 & Group Photo \\
\hline 2017 & Aberdeen & 43 & 18 & 35 & Group Photo \\
\hline 2016 & UCL* & 72 & 19 & 56 & Group Photo \\
\hline 2015 & Southampton & $?$ & $?$ & $?$ & \\
\hline 2014 & Liverpool & 34 & 9 & $?$ & Group Photo \\
\hline 2013 & Cambridge & 65 & 28 & 65 & Attendee List \\
\hline 2012 & Leeds & 56 & 28 & 51 & Attendee List \\
\hline 2011 & Oxford & 40 & 18 & 36 & Attendee List \\
\hline 2010 & Bristol & 43 & 18 & 43 & Attendee List \\
\hline 2009 & Imperial & 32 & 9 & 34 & Attendee List \\
\hline 2008 & Durham & 18 & 4 & 18 & Attendee List \\
\hline
\end{tabular}

Page | 9 
For more detailed analysis we have digitised the information in the programme booklets for each year. This information only captures those who presented either a talk or a poster - for comparison, these numbers are also listed in Table 1. We have focused on gender and ethnicity balance and also the topics and institutions represented by the presentations.

Gender balance between PGRiP talks and posters is shown in Figure 9. Except for 2012, each year has seen more male than female presentations, which perhaps in part reflects the difference in overall numbers of male and female attendees (though in 2018 there was clearly a significant difference in male/female speakers). A similar pattern is evident for posters.
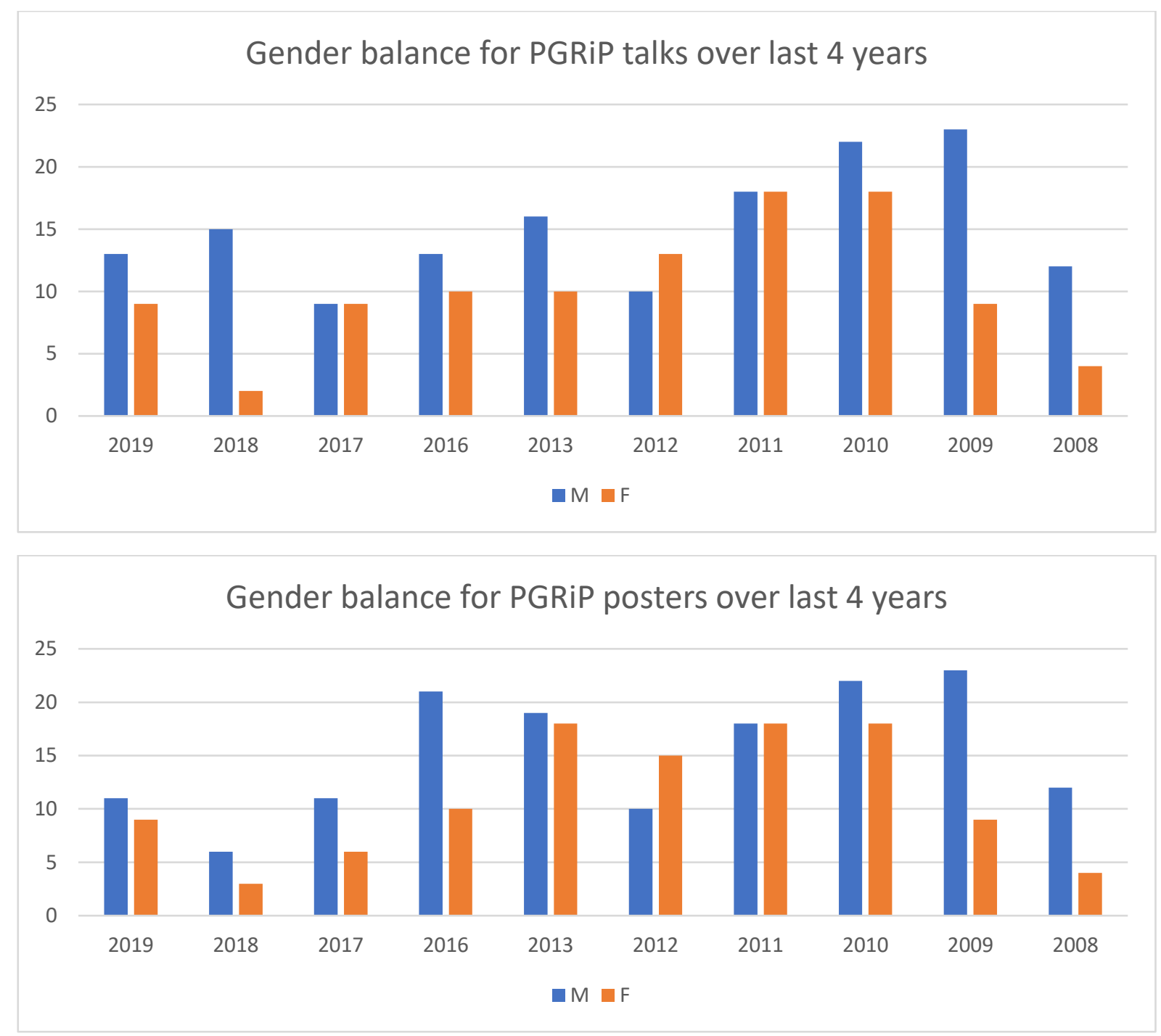

Figure 9. Gender balance across PGRiP talks (top) and posters (bottom).

Figure 10 shows data for PG prizes awarded at PGRiP, with gender and ethnicity defined as before. There are clearly anomalously few female winners of the best talk prize given the ratio of male to female speakers (compare to Figure 9). Ethnicity data show a clear and strong imbalance. The BGA should consider how to widen participation at PGRiP and take measures to ensure that best EDI practice is enacted at PGRiP. 


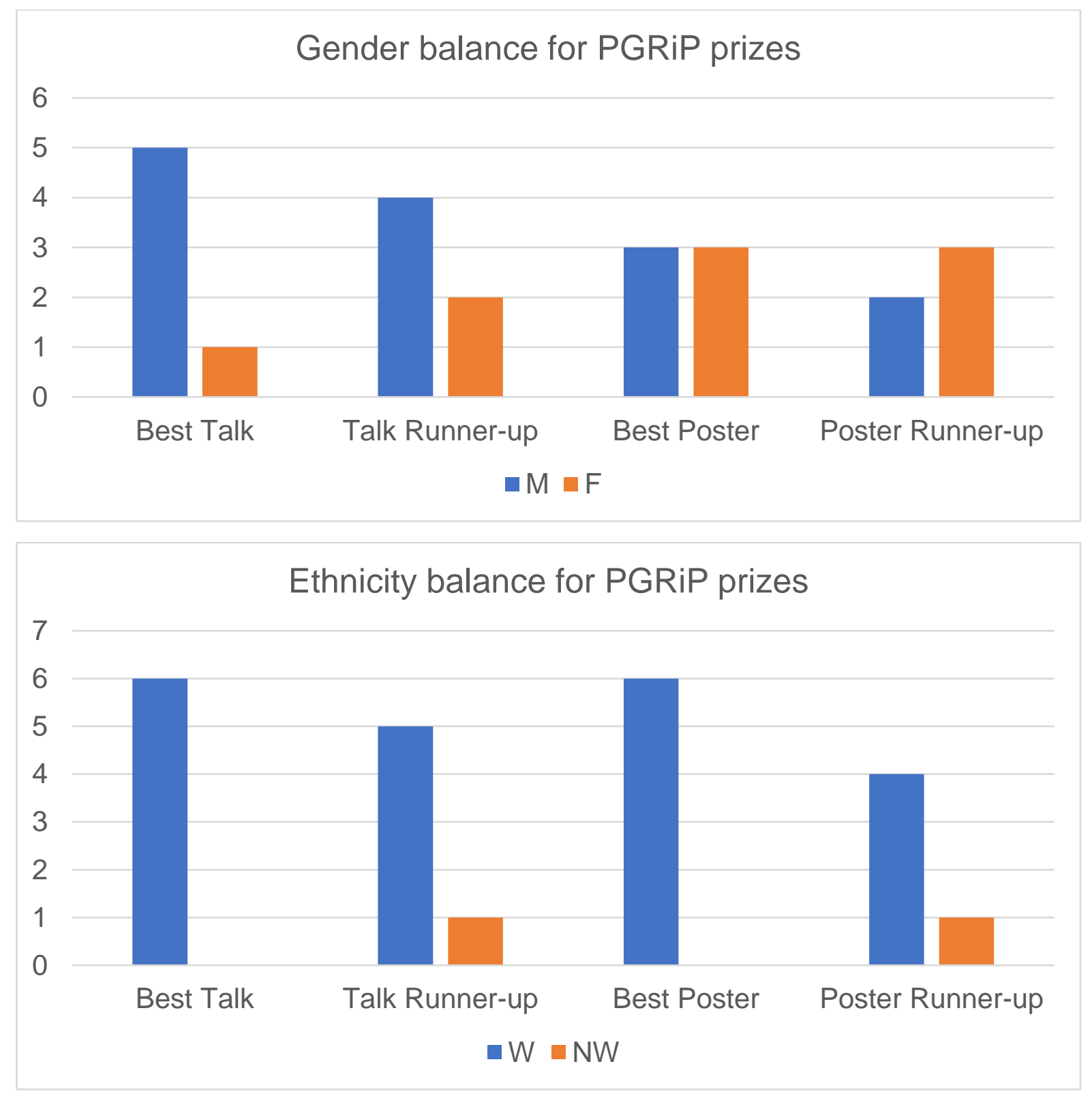

Figure 10. Gender and ethnicity balance for PGRiP prizes.

Figure 11. Lead author affiliation for PGRiP talks (top) and posters (middle) from 2016 - 2019. Bottom shows combined talks and posters for 2008-2011.Figure 11 shows the breakdown of PGRiP talks and posters by the affiliation of the lead author in order to assess whether the BGA is selecting across the breadth of UK institutions. The total number of submissions (posters plus talks) tend to come from a relatively small number of institutions, while submissions from individual institutions generally (though not always) peak when they are the host. This an intuitive result given the likely higher attendance from the host institution because travel and accommodation would not be required for these attendees. Total submissions from Cambridge and Southampton stand out, followed by Imperial and Leeds. There is a relatively low number of total submissions from some UK universities, e.g. Edinburgh, Oxford (in recent times), Leicester, UEA. The BGA committee should look to engage a broader set of institutions to host PGRiP. 

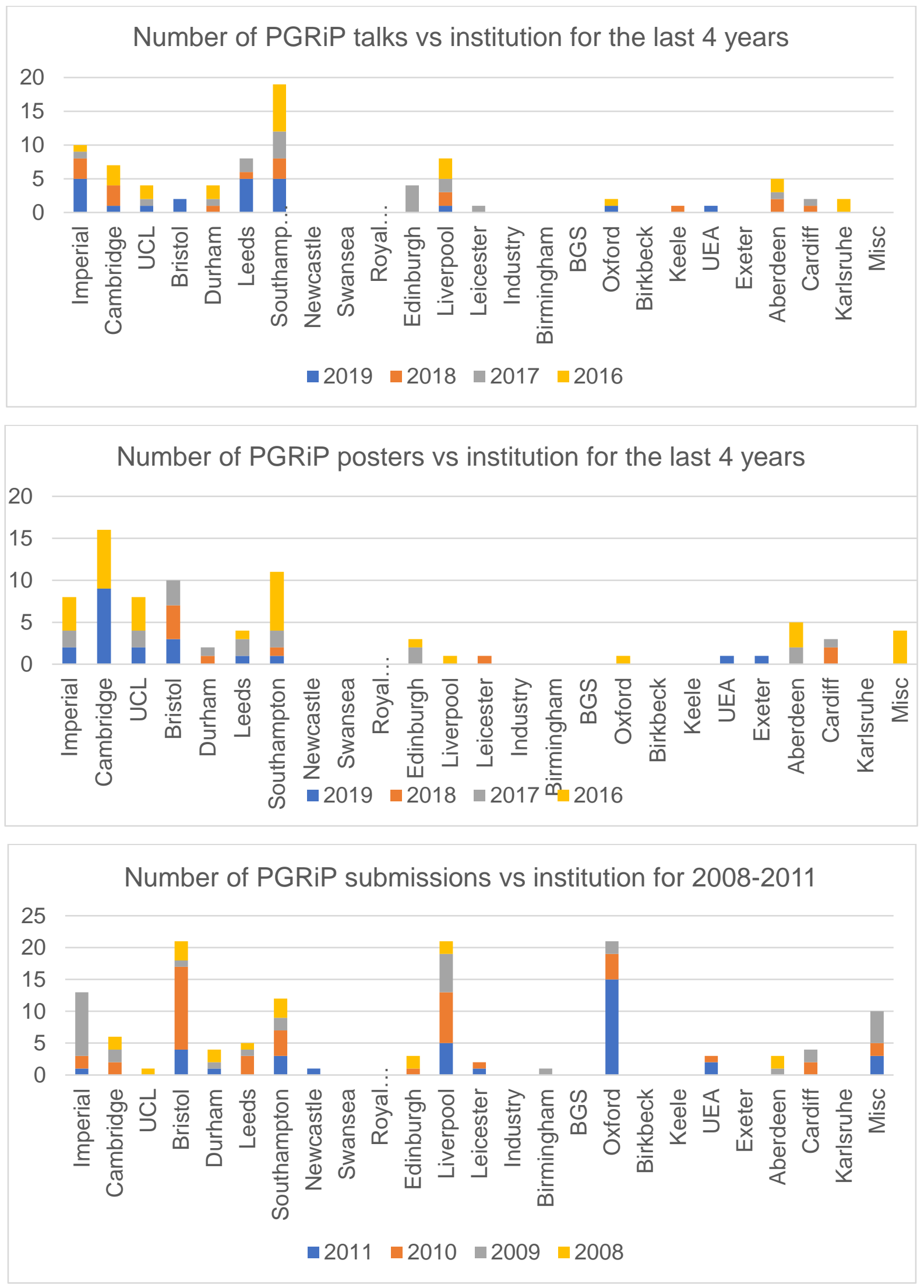

Figure 11. Lead author affiliation for PGRiP talks (top) and posters (middle) from 2016 - 2019. Bottom shows combined talks and posters for 2008-2011. 


\section{Composition of the BGA Committee}

Based on previous minutes recorded by Sheila Peacock, as well as BGA website history, and currently available committee archives, we were able to approximate the gender composition of the committee, shown in Figure 12. Data was missing for the years 2013 and 2019. As above, deciding who was male and who was female is simply based on the names which is a very coarse and uncertain measure.

The male to female balance was very poor prior to 2002 (90\%:10\%); whilst it did improve slightly after this (approximately 70\%:30\%), it hasn't continued to improve and this ratio has stayed approximately constant since 2004 .

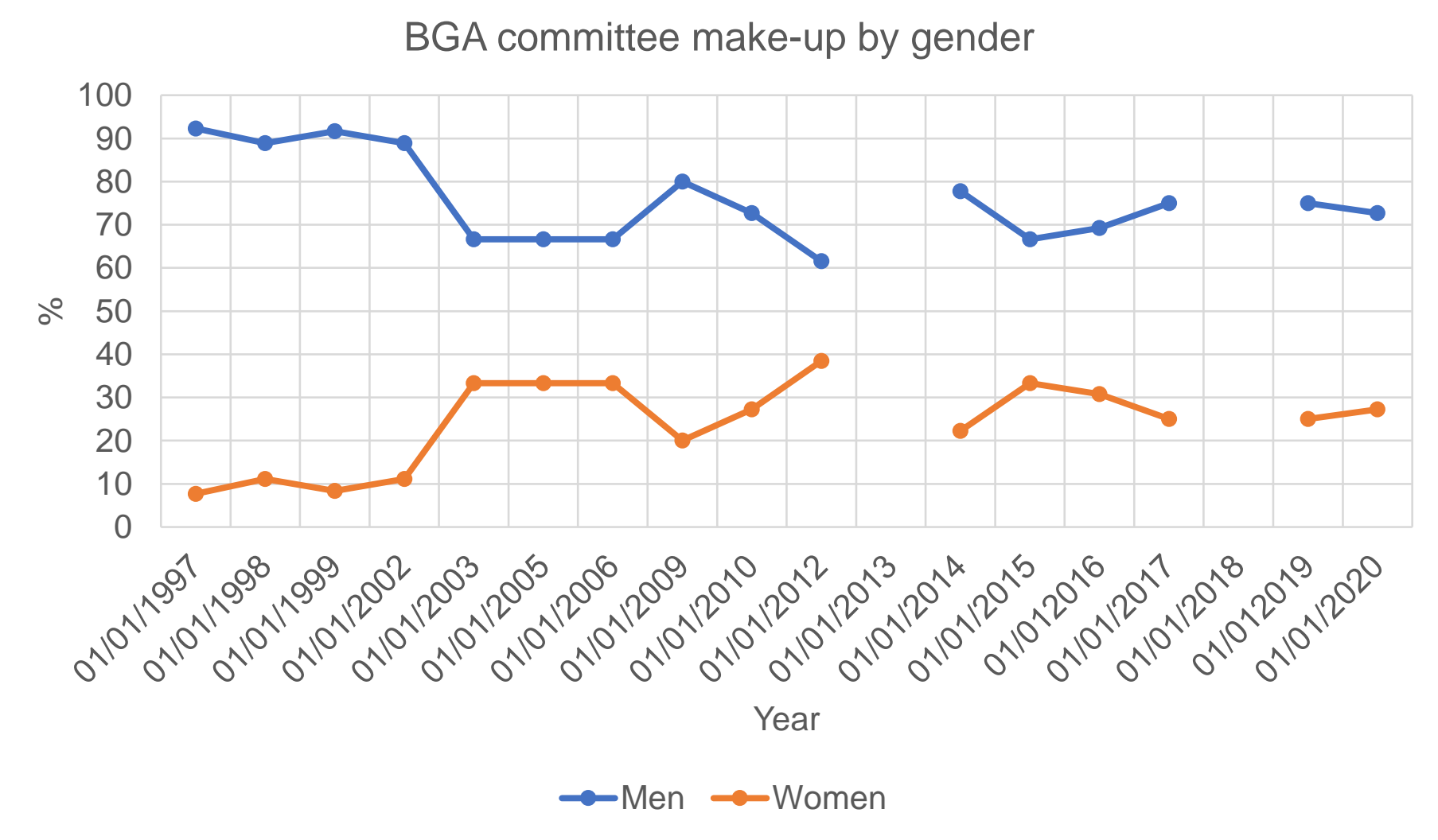

Figure 12. Gender balance of the BGA committee, as determined from historical records. 


\section{Conclusions and future directions}

This report is an initial assessment of community representation and diversity in UK Geophysics, focusing on a range of activities supported by the British Geophysical Association. More work is clearly needed: for example, we have not analysed representation across UK Geophysics faculty or industry. The historical data is also incomplete and so the analysis presented above contains uncertainties that are hard to quantify. With these caveats, the main findings of the data presented in this report are:

1. UK Geophysics, especially in teaching courses and academia, appears to lack ethnic diversity in the areas covered by our data. Future work could also focus on the composition of geophysics faculty staff across UK institutions. We also note that data on industry geophysicists was not within the remit of this report.

2. Women are underrepresented in all areas of BGA activities except recent Bullerwell winners.

3. Attendance at PGRiP is dominated by a small number of institutions and there appears to be a gender imbalance in awarded prizes for oral presentations.

4. There is scope to increase attendance at PGRiP.

5. The BGA committee representation has lacked diversity for many years, without any clear indication of significant improvement. The committee has also generally consisted primarily of academic teaching staff and research fellows and we have not assessed whether its imbalance reflects imbalances in these communities.

The main problem with the present analysis is data availability and quality. We believe that the available data can still provide useful information on EDI in UK Geophysics and on BGA activities when considered in a statistical sense as done here. We also believe that it is important to provide this assessment now using the available data rather than wait for the results from improved data collection strategies, which effectively ignores issues that are already evident. Nevertheless, going forward it is vital that the BGA devises a clear strategy for appropriate data collection. 


\section{Recommendations:}

Below, we set out some initial recommendations as a first step to both improve the opportunities within Geophysics, and acknowledge the achievements of individuals, across all groups.

\subsection{Recommendations for the BGA Committee:}

1. The Annual PGRiP conference provides an excellent platform for research students to showcase their work and interact with others in the community. The Committee should endeavour to increase the accessibility and inclusivity of the conference by:

a) Encouraging diversity in the organising committee to ensure the needs of different groups are accounted for.

b) Supporting conference organisers to develop hybrid offerings which allow both physical and virtual attendance. Where possible, provisions such as childcare should be put in place to maximise opportunities for attendance.

c) Opening up attendance to international PGRs as an opportunity to share research across borders, and to undergraduate students from the host institution to experience post-graduate academia.

d) Requiring unconscious bias training for prize-judging panels and improving panel diversity. For hybrid conferences, in-person and virtual presentations should have separate prize categories to allow for the different styles and resources required.

2. The Committee should conduct a more formal and transparent assessment of the current EDI status within the Geophysics community. This will be done via voluntary questionnaires shared at any event hosted or funded by the BGA, and any funding applications. For example, one area to focus on would be the composition of permanent geophysics staff in UK academia.

3. The Committee should commit to actively promote the work of under-represented members of the community through more diverse awards and nominations. Applicants to awards granted by the BGA will be assessed in line with EDI recommendations and best practices. The BGA should incentivise and support grass-roots initiatives to amplify diverse voices in UK geophysics.

4. Committee members should be selected to ensure a diverse range of candidates. We recognise that being a committee member requires extra work and time, which particularly affects underrepresented groups, such as those with caring responsibilities. Better advertisement of the work typically involved in certain roles could be disseminated to the community prior to electing new members.

5. An EDI Officer should be appointed to the Committee who can oversee the implementation and further development of our recommendations.

6. BGA members are encouraged to set up minority-focussed peer support groups which can be promoted by the BGA.

\subsection{Recommendations for BGA parent societies:}

We encourage GSL and RAS to consider how to improve engagement and accessibility with their activities and services across all demographic groups. In particular:

a) We believe that maintaining a hybrid offering for events going forward will allow more engagement with those unable to attend in person and bring greater benefit to the scientific community. In tandem, improved accessibility to physical meetings is needed, reflecting the diverse backgrounds and circumstances of the UK Geophysics community.

Page | 15 
b) We recommend that the BGA (and other cross-society specialist groups as appropriate) be represented on relevant parent society committees and be involved in joint EDI initiatives and strategies. 


\section{Acknowledgments}

CD is grateful to Victoria Price and LJ Taylor at University of Leeds for help with HESA Data and to Dr. P Koelemeijer for providing PGRiP data.

\section{$\underline{\text { References }}$}

Bernard, Rachel E., and Emily HG Cooperdock. "No progress on diversity in 40 years." Nature Geoscience 11.5 (2018): 292-295. https://doi.org/10.1038/s41561-018-0116-6

Boatright, D., S. Davies-Vollum, and C. King. "Earth science education: The current state of play." Geoscientist 29.8 (2019): 16-19.

Bubeck, Alodie, and Natalie Farrell. "A report on gender diversity and equality at Tectonic Studies Group (TSG) meetings: 2007-2019." (2019). https://doi.org/10.31223/osf.io/p5xf7

Dowey, Natasha, Jenni Barclay, Ben Fernando, Sam Giles, Jacqueline Houghton, Christopher Jackson, Anjana Khatwa et al. "A UK perspective on tackling the geoscience racial diversity crisis in the Global North." Nature Geoscience (2021): 1-4. https://doi.org/10.1038/s41561-021-00737-w.

Gibson, Sally A., Samantha Engwell, and Janine Kavanagh. "The Volcanic \& Magmatic Studies Group Equality, Diversity and Inclusion Report 2020." (2020). https://doi.org/10.31223/osf.io/rgxh7 